\title{
A Study on Developing University Students' Practical Ability and Innovative Ability
}

\author{
Lin $\operatorname{Lin}^{1, a}$ \\ ${ }^{1}$ Institute for Higher Education, Jilin Agricultural University,Changchun,130118, China \\ aemail: linlinjlau@126.com
}

Keywords: University students; Practical abilities; Innovative abilities; Development

\begin{abstract}
Practical ability and innovative ability are two important abilities of university students. They are playing an increasingly prominent role in talent development and market competition. This paper analyzes connotation, features and development goals of university students' practical ability and innovative ability in China's regular higher educational institutions. The focus is on putting forward countermeasures to achieve such a goal.
\end{abstract}

\section{Introduction}

As two important qualities, practical ability and innovative ability are the motivation for a person's all-around development, and also a response to requirements of social development. University students are brought up to be the new force of the future social development. Practical ability and innovative ability are two necessary abilities. They are at the core of implementation of quality-oriented education. To enhance university students' practical ability and innovative ability is not only a new requirement of quality-oriented education in institutions of higher learning, but also an educational development strategy with far-reaching significance.

\section{Connotation of innovative ability and practical ability}

Innovative ability refers to the ability to come up with new ideas and implement the new ideas to create new things; and the ability to keep on turning out new ideas, new theories, new methods and new inventions with economic value, social value and ecological value in the field of science, art, technology and so on relying on knowledge and theories already acquired. It includes three elements, namely innovative thinking ability, non-intelligence element and innovative practice ability. Among them, innovative thinking ability is the key to innovative ability. The essence of practical ability can be explored through comprehensive consideration from the perspective of education, psychology and philosophy. In other words, it refers to physical and psychological abilities required to solve problems in life, social practices and workplace with theoretical knowledge and time skills already acquired ${ }^{[1]}$.

\section{Features of innovative ability and practical ability}

Innovative ability has two salient features-comprehensive uniqueness and structural optimization. Comprehensive uniqueness has to be with one's personality; and structural optimization is an in-depth organic combination, which can contribute to innovation unexpectedly. Practical ability has four features-practical, scenario-based, comprehensive and explicit. Being "practical" is bred through practices, and it is often reflected in practices in life and production. Being "scenario-based" is originated from the purpose of practical ability, that is, "to solve practical problems", and these practical problems are generated in certain scenarios. Being "comprehensive" means the practical problems themselves are comprehensive and to solve them is a reflection of comprehensive abilities. Being "explicit” means practical ability is reflected through practices in life and production, and its development level is also judged by subjects’ practice behaviors. 


\section{Objectives of developing university students' innovative ability and practical ability}

Develop fine personality traits

Innovative talents should be talents with all-around development morally, intelligently, physically and aesthetically. Institutions of higher learning should guide and help students establish a correct outlook on the world, life and values, emphasize on developing their patriotism, honesty and sense of responsibility as well as awareness of entrepreneurship, cooperation and sacrifice, and enhance education of physical and psychological health, humanities and arts. All these aim at fostering students with fine personality traits.

Master consolidate scientific knowledge

Scientific knowledge is the basis for innovation and practices of university students. Only with consolidate scientific knowledge can they get a theoretical basis for their innovation and practices. Only with a full understanding of the latest trend of scientific development can they find a direction for their innovation and practices ${ }^{[2]}$. University students should expose themselves to a wide range of knowledge related to natural sciences, humanities and other subjects as well so as to achieve more fruitful results during their innovation and practices.

Foster an acute innovative awareness

Realize all-around and creative development students with developing students' innovative qualities at the core. Stimulate students' motivation to create things or concepts never existing before. Foster intention, wish and conception of innovation through classroom teaching and learning practices. Improve students' understanding of the value and importance of innovation and sharpen their awareness of innovation to be not content with the present, to keep on making process and to explore the unknown issues and fields. Cultivation of awareness of innovation is the due connotation of quality-oriented education. As an educational concept, its essence lies in development of humans' innovative qualities.

Cultivate a strong practical ability

Practical ability refers to the ability developed to cope with practical problems. It is mainly consists of two aspects. First, the ability reflected in campus teaching practices, including the ability to learn all theoretical knowledge and academic requirements, to participate in all comprehensive experiments and skill training and to expand the range of knowledge and skills and improve their knowledge and skill structure. Second, the ability reflected during their participate in social production and life and to independently analyze and solve a specific problem in a job or a task.

\section{Countermeasures to improve university students' innovative ability and practical ability}

\section{Increase spending}

The government should increase teaching spending for institutions of higher learning. The latter should also diversify its capital sources, including scientific research funds, enterprise donations, individual donations, transfer of scientific achievements, technical services, etc. These capitals can be fully used to improve the current practical teaching conditions, encourage students to participate in scientific innovation activities and foster their innovative ability and practical ability. Besides, the government should give vigorous policy support to institutions of higher learning, thus creating a favorable atmosphere and reliable material guarantee for university students' participation in technological innovation activities ${ }^{[3]}$.

Enhance practice management

Improve institutional construction for practical teaching and guarantee orderly progress of practical teaching. The institutional construction should be in accordance with national laws, regulations and policies, be scientific, standard and operable, and keep on improving during practices. Comprehensive regulations and institutions are a prerequisite for orderly implementation of various links of practical teaching and for effective improvement of the practical teaching management level. Only in this way can practical teaching find rules to follow, clarify rewards and punishments and make their goal of talent development real.

Strength faculty building 
Annually, several practical and innovative education research topics should be launched so as to encourage and support relevant teachers to conduct an extensive theoretical and practical research, summarize their innovative and innovative teaching experiences, and enhance their abilities of practical and innovative teaching. A mechanism which can stimulate teachers to devote themselves to practical and innovative education should be put in place. Specialized rewards should be given to teachers who make new breakthroughs or contributions during practical and innovative teaching. Training of practical and innovative teaching targeted at teachers should be enhanced. The topic training and academic exchange be held on an irregular basis. Besides, the faculty can be organized to visit their counterparts both at home and abroad. All these can contribute to improving the faculty's ability of innovative and practical education.

Improve construction of practice bases

Practical teaching bases and labs are important places to bring up highly-qualified professionals. They are also an essential guarantee for development of students' ability of mastering scientific research methods and improvement of their operational abilities ${ }^{[4]}$. Boost construction of practical teaching bases and labs and embark on a path combining teaching, scientific research, production and multiple disciplines. Break new ground in management methods of lab resources, strengthen intercollegiate communication and cooperation, give full play to advantageous resources of various institutions of higher learning in practical teaching, improve the utilization rate of equipment and instruments and provide technical support for cultivation of students' practical and innovative ability.

\section{Optimization of the evaluation system}

A comprehensive evaluation system of students should be established. In accordance with the cultivation requirements of innovative talents, institutions of higher learning should not just exam students' acquisition and growth of knowledge, but also evaluate changes of their emotions, attitudes, values, innovative awareness, practical abilities, problem-analysis and problem-solving abilities, teamwork and coordination ability. Diversified and qualitative evaluation methods should be adopted. Emphasis should be attached specially to evaluation of students' learning process so as to immediately discover students' changes and progress during the development process and help them better learn themselves, build confidence and tap their development potential. The current examination system should be reformed and the role of examination in ability development should be clarified. The examination content should cover a full range of knowledge, abilities and potential qualities, and contribute to a comprehensive evaluation of students' qualities. The examination forms should be diversified and flexible based on teaching content, classroom discussions and teaching objects. Teachers' teaching practices should be evaluated according to improvement of students' all-around development. The focus on teaching evaluation of teachers should be shifted to on knowledge acquisition, process participation, emotional experiences, cooperation and communication of students ${ }^{[5]}$. Besides, teachers' self-education, self-supervision and self-reflection awareness and abilities should be continuously enhanced, and a new evaluation system for teachers in line with requirements of students' development should be gradually set up. By doing so, institutions of higher learning can achieve an incentive mechanism and management mechanism conducive to cultivation of students' innovative spirit and practical abilities.

\section{Conclusions}

To develop students' innovative spirit and improve their practical ability are an indispensable part of education and teaching reform of institutions of higher learning. They are also historical missions facing institutions of higher learning in the current era. Only by continuously improving students' innovative spirit and practical ability can institutions of higher learning make their students stand out and adapt to requirements of social and scientific development. Therefore, it is necessary for institutions of higher learning to keep on improving their practical teaching system construction, increase their teaching spending, create a favorable practical teaching environment, 
expand the scope of practical teaching, build a platform for students' technological innovation and shape a favorable atmosphere in which students take the initiative to improve their innovative and practical ability.

\section{References}

[1] Lin Haifeng. On deepening practical teaching and improving students' employment abilities [J]. Continue Education Research, 2012, (6).

[2] Yang Qixia. A study on the status of university students' innovative ability, causes and countermeasures [J]. Journal of Educational Institute of Jilin Province, 2011(9).

[3] Zhang Qiming. An investigation and analysis of university students' practical abilities [J]. Journal of Changchun Normal University, 2010(6).

[4] Zhang Baochang. Innovative experimental teaching system: Strengthen cultivation of university students' innovative ability $[\mathrm{J}]$. Journal of Changchun University of Technology, 2010(4).

[5] Chen Pengyong. Innovative practical teaching model: Develop highly-qualified innovative talents $[\mathrm{J}]$. China University Teaching, 2010(5). 